\title{
SERIOUS GAMES VS. TRADITIONAL TOOLS IN CONSTRUCTION SAFETY TRAINING: A REVIEW
}

\author{
Yifan Gao ${ }^{1}$, Vicente A. González ${ }^{2}$, and Tak Wing Yiu ${ }^{3}$
}

\begin{abstract}
For workers, the exposure to on-site hazards can result in fatalities and serious injuries. To improve safety outcomes, different approaches, namely traditional tools (TT), and innovative tools such as serious games (SG), have been implemented into the construction industry. However, evidence suggesting which one is more effective is not apparent. To bridge this gap, a systematic review was conducted to evaluate the literature on TT and SG in this study, and the strengths and weaknesses between them were discussed. The literature findings suggest that the conclusion regarding which one may be more effective is yet inconclusive due to the limitations of existing studies. However, it is noted that the overall performance of SG seems to be superior in several technical aspects mentioned in this paper compared to TT. Based on the findings of this research, we could see the implication that SG may have the potential to become an effective approach for delivering safety training in the construction industry.
\end{abstract}

Keywords: Construction, Safety Training, Serious Games, Traditional Tools.

\section{INTRODUCTION}

\subsection{Safety and Safety Training}

Poor health and safety performance of frontline workers has become a global concern in the construction industry. In 2015/2016, there were 144 fatal claims among all industries in the UK, and the construction sector was responsible for the largest portion with 43 fatalities (HSE, 2016). Similarly, the New Zealand construction sector has become one of the largest industries in causing work-related injuries with claims rising from 25,034 in 2011 to 31,141 in 2015 (ACC, 2016). Serving as the final defence against hazardous environments, the safety behaviour of workers is seen to be critical. Heinrich (1959) reports that $88 \%$ of on-site accidents are induced by risky behaviours.

Safety training is fundamental to enhance safety knowledge and skills of frontline workers. Guo et al. (2012) pointed out that the lack of proper safety training is a key factor to rise on-site injuries. Safety training has been first delivered through traditional tools (TT). The term engaging, which refers to the property of an intervention that entertains potential participants, is utilised to reflect the intrinsic motivation (e.g., enjoyment, interest) of TT. Burke et al. (2006) argues that TT can be distinguished as follows: least engaging (lecture, video, toolbox talk, handout), moderately engaging (computer-based instruction, feedback intervention), and most engaging (hands-on training).

1 PhD. Student, Dept. of Civil and Environmental Engineering, Faculty of Engineering, Univ. of Auckland, Auckland, New Zealand, yga0516@aucklanduni.ac.nz

2 Senior Lecturer, Director of Advanced Computing and Virtual Technologies in Construction (ACVTC) Research Group, Dept. of Civil and Environmental Engineering, Faculty of Engineering, Univ. of Auckland, Auckland, New Zealand, v.gonzalez@auckland.ac.nz

3 Senior Lecturer, Deputy Head of Department, Dept. of Civil and Environmental Engineering, Faculty of Engineering, Univ. of Auckland, Auckland, New Zealand, k.yiu@auckland.ac.nz 
In recent years, virtual reality (VR) and serious games (SG) have emerged as innovative approaches for safety training. $V R$ refers to the virtual experience in computer-simulated virtual environments delivered through the collaboration of hardware and software (Sacks et al., 2013). $S G$ refers to a type of video game developed with the idea of addressing reallife issues (Harteveld, 2010). In SG and VR, trainees are able to accumulate knowledge transfer and develop safety skills by confronting different challenges in virtual environments (e.g., Rüppel and Schatz, 2011). Harteveld (2010) stated the three-world theory to describe the theoretical constructs of a SG: meaning, reality, and play. The world of meaning concerns the learning achievement of users during the gameplay session. The world of reality concerns the realism of simulated virtual environments compared to the actual situations. The world of play concerns the methods used in the game design process with respect to the entertainment aspect. So far, SG have already been extensively used in different areas, such as aviation safety (e.g., Chittaro and Buttussi, 2015), fire drills (e.g., Rüppel and Schatz, 2011, Kobes et al., 2010), healthcare (e.g., Whyte et al., 2015), and construction (e.g., Lin et al., 2011, Guo et al., 2012).

\subsection{Objectives}

The aim of this study is to compare strengths and weaknesses of TT and SG for construction safety training. This aim takes place through the following research objectives:

- To search and review existing literature on safety training utilising TT and SG in construction industry;

- To discuss strengths and weaknesses of the remarkable features between TT and SG, and draw the conclusion on which may be superior.

\section{SySTEMATIC REVIEW FindingS}

\subsection{Research Method}

A systematic review was conducted in July 2016. Search keywords were appended for TT and SG respectively as follows: (construction) AND (safety training) AND (traditional OR passive OR education); (construction) AND (safety training) AND (serious game OR game OR video game). This search was performed on the following databases: ASCE Library, Google Scholar, Taylor \& Francis Online, Scopus, IEEE Xplore, and ScienceDirect. Publications recommended by Scopus and ScienceDirect were also considered. Besides, we marked references and citations from highest cited publications as the second source. During the search round, 569 articles on TT and 132 articles on SG were retrieved. Then, a two-round visual examination was carried out to evaluate the characteristics of the retrieved articles. In this study, the term characteristics represent not only the main content but also the level of relevance. In the first round, we focused on evaluating the titles and abstracts. To reconfirm, full text was examined in the second round. Eventually, 16 articles on TT and 20 articles on SG were included into the final analysis. Due to space limitations, only key publications are mentioned in this paper.

\subsection{Discussion}

In literature, we found that TT for safety training suffer from serious limitations: ignoring the real on-site physical environments (Choudhry and Fang, 2008), failing to take care of workers who have low English proficiency (LEP) and low literacy (LL) (Choudhry and Fang, 2008), failing in attracting trainees' attention (Cherrett et al., 2009), and limited in 
developing workers' spatial awareness ability (Bhoir and Esmaeili, 2015). Instead, the use of SG is perceived to fill in the gaps and bring benefits. The following section discusses TT and SG in a range of technical aspects, and ends up with a comparison of strengths and weaknesses (Table 1).

\subsubsection{Representing the Actual Workplace Situations}

Considering the risk of exposing workers to real situations for hands-on safety training, managers would rather offer off-site training such as lecturing than participating (Guo et al., 2012). As construction process is commonly regarded as rapid and disordered, workers are merely trained to memorise safety materials written in technical jargon in a short time range to raise production efficiency (Guo et al., 2012). Safety knowledge learned in this way seems to be impractical (Guo et al., 2012). In a Hong Kong-based case, interviewed workers claimed that safety meetings, toolbox talks, and on-site morning assemblies were not helpful, stating not only the fact that working on real construction sites was entirely different from how they were trained but also the strong desire that the contents regarding job associated hazards should be mainly considered in safety training (Choudhry and Fang, 2008). In fact, on-site operations of frontline workers appear to be accompanied by various subjects such as disordered housekeeping of materials, and diverse construction equipment. Li et al. (2012) argues the ability of SG in representing unsafe site conditions that "this virtual environment contains all available details, including both temporary and permanent structures, building services, construction material storage, waste, construction equipment and tools." Besides, the state-of-the-art VR and SG techniques have been dramatically improved to perform complex scenarios. By coordinating modelling toolkits (e.g., 3D Studio Max, Sketch Up) and game engines (e.g., Unity 3D), designers can simulate a large variety of on-site elements (Li et al., 2012). Apparently, since TT fail to recreate jobsite realities (Cherrett et al., 2009), SG are superior in this aspect compared to TT.

In terms of the appearance of workplace in SG, two different solutions have been observed in literature: scenario-based, and sandbox-based. Scenario-based solution refers to the style in which users can have limited interaction with fixed scenarios or confined spaces in linear virtual environments, while sandbox-based solution refers to the style in which users can freely explore an extensive landscape in non-linear virtual environments (Dawood et al., 2014). The authors also suggest that sandbox-based solution has advantages in increasing the realism of SG. To the best of our knowledge, the majority of previous efforts of SG identified appear to be built in scenario-based style (e.g., Guo et al., 2012), with the exception of one case (Newton et al., 2013). In this study, users are provided with a virtual space about approximately $1,000 \mathrm{~m}^{2}$ for extensive exploration.

\subsubsection{Text-free Graphical Interfaces}

In New Zealand, there are 7,485 Asian workers, who might suffer LEP and LL, serving in the construction industry (ACC, 2016). In the US, the ratio of LEP workers was more than $71 \%$ in the construction industry according to the Salary Survey run in 2003 (Vazquez and Stalnaker, 2004). Loosemore and Andonakis (2007) found that construction workers tend to have lower educational backgrounds compared to workers in other industries. Having LEP and LL in both English and native languages could lead to knowledge transfer difficulties. In literature, TT are shown to be heavily text-based while delivering safety knowledge with video, lecture, handout, and toolbox talk. Especially, written materials seem to be fruitless in educational interventions (Gagliano, 1988). Being interviewed, an uneducated worker stated that he could not understand the safety documents and found difficulty in communicating during safety meetings (Choudhry and Fang, 2008). To 
address this issue, a number of construction corporations have translated safety materials into required languages and hired dual-language instructors (Sokas et al., 2009). However, Medhi et al. (2006) observes that users tend to prefer text-free interfaces to text-based appearances. For instance, in a SG based study in construction safety, one participant, who uses English as the second language, claimed that his learning process was well commenced in the game approach due to the few texts included (Greuter and Tepe, 2013). The evidence seems to indicate that the use of 3D virtual workplaces in safety training should be able to mitigate the language issues. Thus, SG are perceived to deliver new possibilities for workers who are struggling with LL and LEP issues (e.g., Guo et al., 2012).

\subsubsection{Engagement}

The evidence suggests that TT are ineffective in terms of knowledge transfer, which is highly because TT are less engaging and trainees' attention is poor at best (Cherrett et al., 2009). Instead, it is argued that SG immerse players well in scenarios by maintaining their interests with the senses of presence, flow, and character identification (Bachen et al., 2016). In particular, presence refers to players' psychological illusion of feeling involved. Flow refers to the phenomenon that players are shown to lose the track of time while the game contents challenge largely their knowledge and skills. Character identification refers to the instinctive behaviour in which players adopt the identities and goals from virtual avatars as personal attributes. We were not able to fully support the advantages of using SG instead of TT for safety training using the existing literature, due to the fact that TT and SG studies were developed under different methodological, conceptual and practical assumptions. Besides, studies analysed are spread across 20 years while VR and SG technology were in its infancy 20 years ago. Therefore, valid comparisons are difficult. However, Chittaro and Buttussi (2015) found promising evidence of the SG application in the aviation area, where the group treated with immersive SG reported higher engaging levels and knowledge retention scores compared to the control group treated with TT.

\subsubsection{Situational Awareness}

Accidents often happen when workers focus the required attention on tasks and forget to account for hazards in the surroundings, such as unguarded floor openings, uncovered scaffolds, among others. Workers' situational awareness, which refers to the ability of perceiving surroundings, copes with accidents caused by distraction (Bhoir and Esmaeili, 2015). The authors also note that frequently being exposed to virtual environments contributes to the development of this ability among workers. Besides, Green and Bavelier (2006) suggest that playing video games may contribute to the improvement in players' capability in allocating attention, which represents the ability of tracking two items at the same time. Based on this finding, we consider that well-thought-out SG should have the analogic potential in equipping workers with spatial perception and attention allocation capability, instead of TT.

\subsubsection{Other Technical Aspects}

In addition, we investigated other SG technical aspects when compared to TT.

- A large number of on-site tasks occupy more than one worker at the same time. SG can offer multi-collaboration experience to trainees (e.g., Guo et al., 2012).

- In $S G$, the egocentric interface allows trainees to be in charge of their learning experience by exploring and progressing at their own will (Bhoir and Esmaeili, 2015), which is supported by the use of game managers including restart, exit, load, 
save, and pause (Thorn and Arer, 2014). Thus, learning should be more proactive in SG.

- In SG, the reward system is able to raise trainees' motivation (Cruz-Cunha, 2012), including incentives such as cash and health power-ups (Thorn and Arer, 2014).

- Movement trackers can be utilised to trace behaviours during the gameplay process (Kobes et al., 2010). The reliability of data collected can be better guaranteed in SG compared to the self-report method used in TT.

- In SG, the storyline can effectively engage players by letting them participate as protagonists (Baranowski et al., 2008).

- In TT, the arrangement of safety drill should risk trainees' safety at danger. In SG, workers can encounter hazards without carrying heavy psychological burden of getting injured, which brings new opportunities in analysing human behaviours under extreme conditions (Rüppel and Schatz, 2011).

- In SG, hazards can be designed at different challenging levels on the basis of users' safety knowledge demand (e.g., Lin et al., 2011). Learning in this way appears to be perfectly tailored.

- Since SG are accessible at home, the repetitive exposure can consolidate the knowledge transfer (Chittaro, 2012).

- Since not every worker is skilled in using computers, the complex 3D navigation controllers in SG could be confusing (e.g., Guo et al., 2012). Thus, age is a factor to be considered in the SG design.

- In some SG, the 3D navigation controller is too complex to raise players' cognition of operating in an artificial game environment, which might negatively impact players' supposed actual reactions towards hazards (e.g., Guo et al., 2012).

- Skilful game players already get used to fierce scenarios. The educative nature might have little influence on this type of crowd (Smith and Trenholme, 2009).

\subsubsection{Costs}

SG: The evidence seems to indicate that the making of SG, which commonly comes with a non-commercial development, requires some capital investment mainly in hardware. For software development, game engines (e.g., Unity 3D), 3D models (e.g., building elements, avatars, vehicles) and 2D textures (e.g., weather, particle systems) are particularly economical for developers. For hardware purchase, however, funding is mostly spent on workstations, gameplay platforms (e.g., PlayStation), virtual reality sets (e.g., headmounted display, trackers). Newton et al. (2013) pointed out that the budget taken to accomplish a video game in construction education in their case was approximately $\$ 50,000$ for software development and $\$ 600$ apiece for basic hardware purchase, covering the payment for students as developers from Architectural Computing and all the aforementioned expenditures. However, when developed, SG can be distributed as lowpriced mobile apps or video games for workstations. When VR is introduced, headmounted display can imply some investment ( $\$ 600$ Oculus Rift) plus a workstation with suitable graphic capabilities. This is increasingly more accessible technology for users at reasonable prices.

TT: However, the related evidence towards the costs on TT has been elusive, with one study suggesting a slight hint of a $\$ 500$ enrolment fee for each trainee (Forst et al., 2013). 


\subsubsection{Effectiveness}

It appears that the statistical proof towards the effectiveness of TT and SG is scarce and confusing. The work of Girard et al. (2013), including a meta-analysis of recent SG studies, suggests that the affirmation of the effectiveness towards SG is seen to be challenging due to serious limitations of existing studies included in their study. In literature, we could see the same difficulties on TT and SG studies in the construction safety area, such as the lack of rigorous assessment, the use of different intangible indicators between studies, and the research basis of qualitative rather than quantitative. Therefore, reliable evidence suggesting the effectiveness of TT and SG is still lacking.

\subsubsection{Comparison}

In this section, strengths and weaknesses between SG and TT were compared using aforementioned findings (Table 1).

Table 1: Summary of Strengths and Weaknesses

\begin{tabular}{cll}
\hline Approach & \multicolumn{1}{c}{ Strengths } & \multicolumn{1}{c}{ Weaknesses } \\
\hline SG & Simulate actual workplace dynamics. & Computer skills required. \\
& Text-free Graphical Interfaces. & Complex 3D navigation. \\
& Higher knowledge retention. & Less effective for skilful players. \\
& Engagement and interactivity. & \\
& Stimulate situational awareness. & \\
& Multi-collaboration. & \\
& Egocentric interface. & \\
& Reward system and storyline. & \\
& Data reliability. & \\
& Risk-free and accessible at home. & \\
& Alternative challenges levels. & Inapplicable for on-site situations. \\
TT & Suitable for unskilled computer users. & Difficult for LL and LEP. \\
& Instructors interpret safety knowledge. & Less engage. \\
& Hands-on practice allows interaction. & Unsatisfied knowledge retention. \\
\hline & Easy-carrying educational materials. & \\
\hline
\end{tabular}

\section{CONCLUSION}

In this study, a systematic review has been conducted to address the characteristics of TT and SG. Given that, the effectiveness of TT and SG has not been justified due to a couple of serious limitations of previous studies included in this research. However, the qualitative comparison made between TT and SG leads us to think that SG are more powerful than TT in improving safety training in a number of technical aspects. Since the SG virtual environments can represent site dynamics, safety knowledge learned in this way can be more effective and applicable. By interacting with a game environment, trainees are able to raise their spatial awareness abilities significantly. Besides, SG could offer new opportunities not only for trainees facing LL and LEP issues, but also for 
researchers to investigate human behaviour under extreme conditions. In conclusion, SG research is a promising area to construction safety training based on the findings and deeper investigation on the SG effectiveness is required to unfold the real potential of SG.

\section{REFERENCES}

ACC. 2016. New Zealand.

Bachen, C. M., Hernández-Ramos, P., Raphael, C., and Waldron, A. 2016. How do presence, flow, and character identification affect players' empathy and interest in learning from a serious computer game? Computers in Human Behavior, 64, 77-87.

Baranowski, T., Buday, R., Thompson, D. I., and Baranowski, J. 2008. Playing for Real: Video Games and Stories for Health-Related Behavior Change. American Journal of Preventive Medicine, 34, 74-82.

Bhoir, S. and Esmaeili, B. State-of-the-art review of virtual reality environment applications in construction safety. Proceedings of the AEI Conference 2015, 2015. 457468.

Burke, M. J., Sarpy, S. A., Smith-Crowe, K., Chan-Serafin, S., Salvador, R. O., and Islam, G. 2006. Relative effectiveness of worker safety and health training methods. American Journal of Public Health, 96, 315-324.

Cherrett, T., Wills, G., Price, J., Maynard, S., and Dror, I. E. 2009. Making training more cognitively effective: Making videos interactive. British Journal of Educational Technology, 40, 1124-1134.

Chittaro, L. 2012. Passengers' Safety in Aircraft Evacuations: Employing Serious Games to Educate and Persuade. In: Bang, M. \& Ragnemalm, E. L. (eds.) Persuasive Technology. Design for Health and Safety: 7 th International Conference, PERSUASIVE 2012, Linköping, Sweden, June 6-8, 2012. Proceedings. Berlin, Heidelberg: Springer Berlin Heidelberg.

Chittaro, L., and Buttussi, F. 2015. Assessing knowledge retention of an immersive serious game vs. A traditional education method in aviation safety. IEEE Transactions on Visualization and Computer Graphics, 21, 529-538.

Choudhry, R. M., and Fang, D. 2008. Why operatives engage in unsafe work behavior: Investigating factors on construction sites. Safety Science, 46, 566-584.

Cruz-Cunha, M. M. 2012. Handbook of Research on Serious Games as Educational, Business and Research Tools, IGI Global.

Dawood, N., Miller, G., Patacas, J., and Kassem, M. 2014. Construction health and safety training: the utilisation of 4D enabled serious games. Journal of Information Technology in Construction, 19, 326-335.

Forst, L., Ahonen, E., Zanoni, J., Holloway-Beth, A., Oschner, M., Kimmel, L., Martino, C., Rodriguez, E., Kader, A., Ringholm, E. \& Sokas, R. 2013. More than training: Community-based participatory research to reduce injuries among hispanic construction workers. American Journal of Industrial Medicine, 56, 827-837.

Gagliano, M. E. 1988. A literature review on the efficacy of video in patient education. Academic Medicine, 63, 785-92.

Girard, C., Ecalle, J. \& Magnan, A. 2013. Serious games as new educational tools: How effective are they? A meta-analysis of recent studies. Journal of Computer Assisted Learning, 29, 207-219.

Green, C. S., and Bavelier, D. 2006. Enumeration versus multiple object tracking: the case of action video game players. Cognition, 101, 217-245. 
Greuter, S. \& Tepe, S. 2013. Engaging students in OH\&S hazard identification through a game. 6th Digital Games Research Association (DiGRA) Conference, At Georgia Institute of Technology, Atlanta, Georgia.

Guo, H., Li, H., Chan, G., and Skitmore, M. 2012. Using game technologies to improve the safety of construction plant operations. Accident Analysis and Prevention, 48, 204-213.

Harteveld, C. 2010. Triadic game design, London: Springer.

Heinrich, H. 1959. Basic philosophy of accident prevention. Industrial accident prevention. A scientific approach. 4a. ed, New York, McGraw-Hill.

HSE. 2016. Health and Safety Executive.

Kobes, M., Helsloot, I., De Vries, B., and Post, J. 2010. Exit choice, movement time and evacuation behaviour in hotel fire evacuation. Procedia Engineering, 3, 37-51.

Li, H., Chan, G. \& Skitmore, M. 2012. Visualizing safety assessment by integrating the use of game technology. Automation in Construction, 22, 498-505.

Lin, K. Y., Son, J. W., and Rojas, E. M. 2011. A pilot study of a 3D game environment for construction safety education. Electronic Journal of Information Technology in Construction, 16, 69-83.

Loosemore, M. \& Andonakis, N. 2007. Barriers to implementing OHS reforms - The experiences of small subcontractors in the Australian Construction Industry. International Journal of Project Management, 25, 579-588.

Medhi, I., Sagar, A. \& Toyama, K. Text-free user interfaces for illiterate and semi-literate users. Information and Communication Technologies and Development, 2006. ICTD'06, 72-82.

Newton, S., Lowe, R., Kember, R., Wang, R. \& Davey, S. 2013. The Situation Engine: A Hyper-Immersive Platform for Construction Workplace Simulation And Learning. Proceedings of the $13^{\text {th }}$ International Conference on Construction Applications of Virtual Reality, 30-31, October, 2013, London, UK.

Rüppel, U., and Schatz, K. 2011. Designing a BIM-based serious game for fire safety evacuation simulations. Advanced Engineering Informatics, 25, 600-611.

Sacks, R., Perlman, A., and Barak, R. 2013. Construction safety training using immersive virtual reality. Construction Management and Economics, 31, 1005-1017.

Smith, S. P., and Trenholme, D. 2009. Rapid prototyping a virtual fire drill environment using computer game technology. Fire Safety Journal, 44, 559-569.

Sokas, R. K., Emile, J., Nickels, L., Gao, W., and GITTLEMAN, J. L. 2009. An intervention effectiveness study of hazard awareness training in the construction building trades. Public health reports, 124 (1), 160-168.

Thorn, A. \& Arer, M. S. 2014. Pro Unity Game Development with C\#, Springer.

Vazquez, R. F., and Stalnaker, C. K. Latino Workers in the Construction Industry Overcoming the language barrier improves safety. The $1^{\text {st }}$ International Conference in Safety and Crisis Management in the Construction, Tourism and SME Sectors, 2004, Nicosia, Cyprus. 24-28.

Whyte, E. M., Smyth, J. M., and Scherf, K. S. 2015. Designing Serious Game Interventions for Individuals with Autism. Journal of Autism and Developmental Disorders, 45, 3820-3831. 